\title{
Experimental Verification and Accuracy Improvement of Gas Entrapment and Shrinkage Porosity Simulation in High Pressure Die Casting Process*
}

\author{
Yukio Otsuka \\ School of System Engineering, Kochi University of Technology, Kami 782-8502, Japan
}

In recent years, computer simulation, that is molten metal flow and solidification analysis, has become very important tool for optimal casting and casting plan design. The analysis accuracy was, however, insufficient because of complicate phenomena and difficulty of experiments especially in high pressure die casting process. In this study, effects of various analysis conditions in simple aluminum sand casting were investigated by existing experiments. And subsequently, in actual high pressure die casting experiments for measurement of molten metal pressure, air-pressure, solidification and casting defects especially gas entrapment and shrinkage porosity, computer simulation results of airpressure, solidification, and those defects were verified. [doi:10.2320/matertrans.F-M2013835]

(Received May 16, 2013; Accepted October 3, 2013; Published November 15, 2013)

Keywords: computer simulation, molten metal flow, solidification, high pressure die casting, experimental verification, accuracy

\section{Introduction}

In recent years, computer simulation that is CAE technology has made rapid progress, and in die casting industry it has become very important and urgent problem to optimize casting design and casting plan for improvement of quality, function, light-weighting, delivery time and cost by using CAE effectively. The development of casting solidification simulation has started by investigation of 2-dimensional solidification analysis in 1960's and followed by 3-dimensional expansion, prediction method of shrinkage cavity, high speed computation, and large computation, and it has been thought to reach almost practical phase. In the other side, flow simulation has started by basic development of flow analysis method in 1980's, and follows by 3dimensional expansion, improvement of computation speed and accuracy. ${ }^{1-3)}$

In this way, improvement of casting simulation accuracy is in progress, however, it is in insufficient phase especially in die casting simulation because of difficulty of experimental verification, and complicated phenomena. In this work for improvement of simulation accuracy, effects of various analysis conditions in simple aluminum sand casting are investigated by existing experiments. And subsequently, in actual high pressure die casting experiments for measurement of molten metal pressure, air-pressure, solidification and casting defects especially gas entrapment and shrinkage porosity, computer simulation results of air-pressure, solidification, and those defects were verified.

\section{Analysis Method of Molten Metal Flow and Solidification}

2.1 Numerical method of flow and solidification analysis Flow analysis of non-compressive fluid with free surface can be calculated by MAC (Marker And Cell) method, SMAC (Simplified MAC) method, SOLA (Solution Algorithm) method, SOLA-VOF (Volume of Fluid) method,

*This Paper was Originally Published in Japanese in J. JFS 85 (2013) 92-98. etc. $^{4,5)}$ In these years SOLA-VOF method has been mostly used, and it is used in this study because of the short calculation time and calculation accuracy. In the analysis method, velocity and pressure in rectangular mesh is defined, and the temporary predicted value is calculated by explicit solution of motion equation. And modification operation of pressure and velocity value is iteratively executed until satisfaction of continuity equation. In this way the velocity of each element is calculated by SOLA method, and the free surface shape in next time step is calculated by VOF method. Molten metal flow is simulated by those procedures. Staggered grid is used in this work, and pressure is defined in the center of grid, and velocity is defined on the boundary. In complete slip condition on the boundary, normal component of velocity on the boundary is zero, and tangential component have no gradient in normal direction on the boundary. On the other hand, in non-slip condition all components of velocity on the boundary are set zero. Solidification is calculated by finite difference method, and latent heat is calculated by temperature recovery method. ${ }^{6}$ Application program in this work is developed on base of commercial casting software TopCAST (version 2005). ${ }^{7)}$

\subsection{Calculation method for back air-pressure}

In die casting process, back pressure of air and various gas in die cavity by molten metal flow is important phenomenon, and it affects on molten metal flow. Because of very short filling time and difficulty of gas-discharge especially in highpressure die casting, back pressure is highly raised to act on free surface. In case of no discharge, gas volume and pressure are calculated by state equation assumed isothermal at each time step of mold filling. In case of discharge from air-vent slit etc., gas volume and pressure are calculated by state equation taking account of discharged gas acquired by sequential steady calculation at each time step. And the calculated pressure value, that is back pressure, is assumed to affect on molten metal surface. Air vent usually used in high pressure die casting process have narrow slit shape. Gas flow in narrow slit can be assumed Poisseuille's flow between narrow parallel plates, and gas discharge volume $Q$ is calculated by eq. $(1)^{8)}$ 


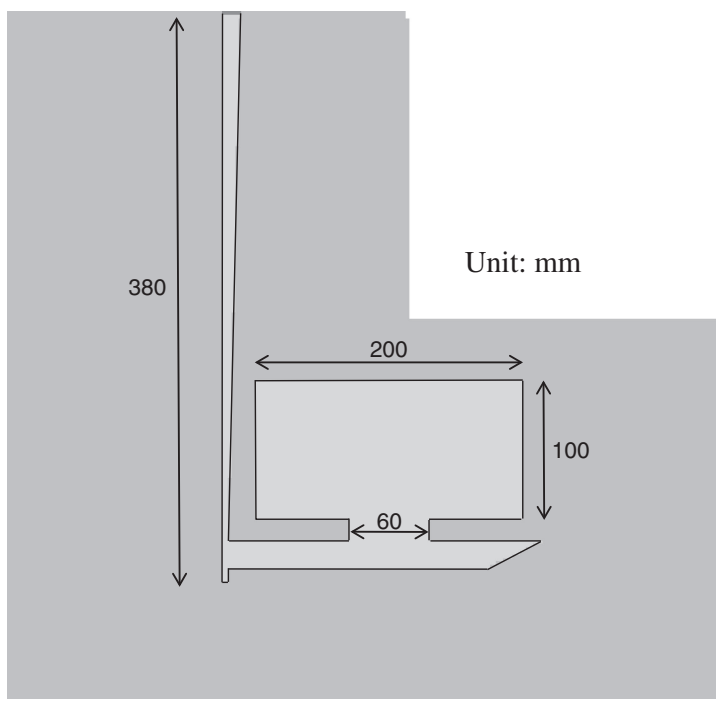

Fig. 1 Experimental aluminum casting and sand mold.

$$
Q=2 \Delta p \cdot t^{3} \cdot w /(3 \mu \mathrm{L})
$$

Here, $\Delta p$ is gas pressure difference between inner cavity and out of vent, $2 t$ is air vent gap width, $w$ is air vent width, $\mu$ is viscosity coefficient of the air, $L$ is air vent length.

Equation (1) is assumed in laminar flow in narrow gap, in case of wider gap and higher speed flow, however, laminar flow transit to turbulent flow. In this study the eq. (1) is used for practical method of vent effect.

\section{Verification in Simple Sand Cast Model}

\subsection{Calculation condition of simple sand casting}

Thermocouple is generally used for verification of solidification analysis, and lots of experiments have been done. On the other hand as for mold filling, actual observation through transparent heat-resistant glass, or by X-ray have become to be carried out with difficulty in recent years. Concerning X-ray observation Campbell et al. made a benchmark test in aluminum sand casting. ${ }^{9)}$ In this work those experimental results is compared with computed results. In this computed conditions back pressure is assumed to be ignored because mold filling time is relatively long and gas in mold cavity escapes through sand mold.

(1) Casting and Sand mold (Fig. 1)

Plain casting $(200 \mathrm{~mm}$ width, $100 \mathrm{~mm}$ height, $10 \mathrm{~mm}$ thickness), and Casting plan (Sprue $380 \mathrm{~mm}$ height, Lower runner $15 \mathrm{~mm}$ width and $20 \mathrm{~mm}$ height, Ingate $60 \mathrm{~mm}$ width, $10 \mathrm{~mm}$ thickness and $15 \mathrm{~mm}$ length)

(2) Mesh model (Fig. 2)

Mesh size $(2.5 \mathrm{~mm}$, or $5 \mathrm{~mm}$ ), Sand mold (same, not illustrated)

(3) Conditions for calculation method

Analysis type: molten metal flow, and solidification

Flow on boundary: basically complete slip condition, and additionally non slip condition

Injection speed: $0.89 \mathrm{~m} / \mathrm{s}$

Cavity back pressure, and surface tension: none

(4) Applied physical and thermal properties for calculation

Casting alloy (pure aluminum): specific heat (0.963

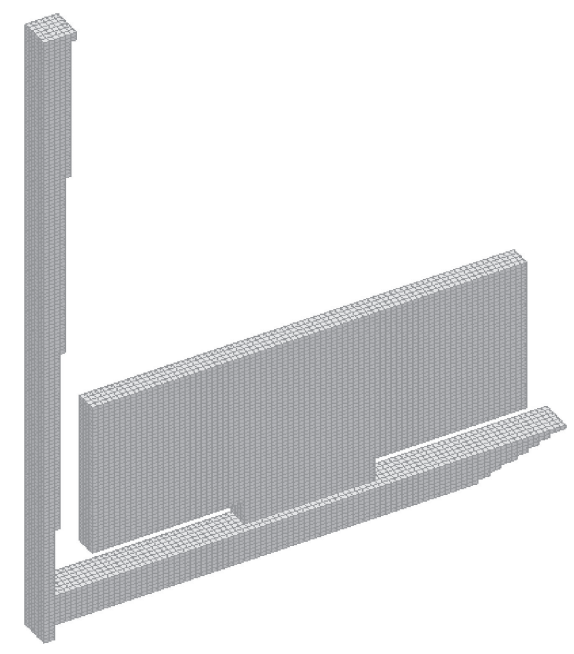

Fig. 2 Mesh model of aluminum sand casting (example of $2.5 \mathrm{~mm}$ mesh).

$\mathrm{kJ} / \mathrm{kgK})$, density $\left(2650 \mathrm{~kg} / \mathrm{m}^{3}\right)$, thermal conductivity (126.6 $\mathrm{W} / \mathrm{mK})$, solidification temperature $(933 \mathrm{~K})$, latent heat $\left(389.3 \mathrm{~kJ} / \mathrm{kg}\right.$ ), kinematic viscosity (basically $0.01 \mathrm{~cm}^{2} / \mathrm{s}$, and additionally $\left.0.0043 \mathrm{~cm}^{2} / \mathrm{s}\right)$

Sand mold: specific heat $(0.8730 \mathrm{~kJ} / \mathrm{kgK})$, density $(1500$ $\left.\mathrm{kg} / \mathrm{m}^{3}\right)$, thermal conductivity $(0.63 \mathrm{~W} / \mathrm{mK})$

Heat transfer coefficient: between casting and mold $\left(837 \mathrm{~W} / \mathrm{m}^{2} \mathrm{~K}\right)$

(5) Initial condition: Pouring temperature (973 K), Sand mold (293 K)

\subsection{Verification results between analysis and experi- ments}

Flow simulation results corresponding to X-ray observation results of Campbell et al. are shown in Fig. 3. At first, about the result of base analysis condition Fig. 3(a), after $0.5 \mathrm{~s}$ molten metal runs on the bottom of lower runner, runs into end of lower runner, and flow back. After $0.75 \mathrm{~s}$, it is spouted out through under gate, spreads in the bottom of casting cavity after $1.0 \mathrm{~s}$, and after $1.25 \mathrm{~s}$ it moves upward with surface waving. Surface is not horizontal, the surface rises on the upper right, and finally it fills up after $2.0 \mathrm{~s}$. These result shows relatively good correspondence with the results obtained by X-ray observation. Next, comparing (a) base (complete slip) condition with (b) non-slip condition on surface of mold, molten metal flows with flat surface in the latter case. If sufficient number of mesh could be used in the direction of wall thickness, non-slip condition should be applied. In this case of 4 elements in the direction of wall thickness, however, non-slip condition should be applied for better accuracy. Thinking of present computer ability, element number used have a limit, therefore molten metal through narrow gap with 1 or 2 elements is thought to have excessive non-slip effect. In present computer level, complete slip condition for thin wall castings is thought to be more practical.

Next in case (c) of lower value of kinematic viscosity, flow pattern change is shown. After 0.5 to $1.0 \mathrm{~s}$, molten metal runs to end of runner more quickly. Viscosity in actual casting raise in proportion to solidification progress, so kinematic viscosity value depending on temperature should be applied. Thinking increase of computing time, however, constant viscosity of molten metal is generally used. 


\begin{tabular}{|c|c|c|c|c|c|c|c|c|}
\hline \multirow{2}{*}{$\begin{array}{l}\text { Analysis } \\
\text { condition } \\
\text { (a)base }\end{array}$} & & & 5 & E & - & 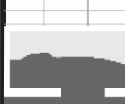 & & \\
\hline & $0.25 \mathrm{~s}$ & $0.50 \mathrm{~s}$ & $0.75 \mathrm{~s}$ & $1.00 \mathrm{~s}$ & $1.25 \mathrm{~s}$ & $1.50 \mathrm{~s}$ & $1.75 \mathrm{sec}$ & $2.00 \mathrm{~s}$ \\
\hline \multirow{2}{*}{$\begin{array}{l}\text { (b)Non- } \\
\text { slip }\end{array}$} & & & & & 5 & L & & 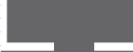 \\
\hline & $0.25 \mathrm{~s}$ & $0.50 \mathrm{~s}$ & $0.75 \mathrm{~s}$ & $1.00 \mathrm{~s}$ & $1.25 \mathrm{~s}$ & $1.50 \mathrm{~s}$ & $1.75 \mathrm{~s}$ & $2.00 \mathrm{~s}$ \\
\hline \multirow{3}{*}{$\begin{array}{l}\text { (c)Low } \\
\text { viscosity }\end{array}$} & 1 & & 1 & & 1 & 1 & & \\
\hline & & - & -1 & 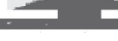 & $5=$ & 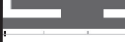 & $=$ & $=$ \\
\hline & $0.25 \mathrm{~s}$ & $0.50 \mathrm{~s}$ & $0.75 \mathrm{~s}$ & $1.00 \mathrm{~s}$ & $1.25 \mathrm{~s}$ & $1.50 \mathrm{~s}$ & $1.75 \mathrm{~s}$ & $2.00 \mathrm{~s}$ \\
\hline \multirow{2}{*}{$\begin{array}{l}\text { (d)Coarse } \\
\text { mesh }\end{array}$} & & & & & & & & \\
\hline & $0.25 \mathrm{~s}$ & $0.50 \mathrm{~s}$ & $0.75 \mathrm{~s}$ & $1.00 \mathrm{~s}$ & $1.25 \mathrm{~s}$ & $1.50 \mathrm{~s}$ & $1.75 \mathrm{~s}$ & $2.00 \mathrm{~s}$ \\
\hline (e)Stair- & & & & & & 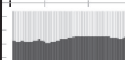 & & \\
\hline mesh & $0.25 \mathrm{~s}$ & $0.50 \mathrm{~s}$ & $0.75 \mathrm{~s}$ & $1.00 \mathrm{~s}$ & $1.25 \mathrm{~s}$ & $1.50 \mathrm{~s}$ & $1.75 \mathrm{~s}$ & $200 \mathrm{~s}$ \\
\hline
\end{tabular}

Fig. 3 Analysis conditions (a) (b) (c) (d) (e) and simulation results of molten metal flow.

Effect of mesh size is relatively large, molten metal flow in case (d) of coarse mesh $(5 \mathrm{~mm})$ shows less waves or splashes and can not be observed small action. However, calculation time decreases drastically from $503 \mathrm{~s}(2.5 \mathrm{~mm})$ to $27 \mathrm{~s}(5 \mathrm{~mm})$ in use of Pentium $31 \mathrm{GHz}$, because of less number of element, and larger time step. In case of quick analysis for rough flow pattern, coarse mesh model can be useful.

In case of different mesh-direction, (e) case (45 degrees rotation around $z$-axis), mesh model of plane transform to model with stepwise surface. Flow resistance occur in this case, and molten metal after $0.5 \mathrm{~s}$ does not run in cavity, and gradually fill the lower runner. This tendency is thought to be remarkable in castings with thinner wall. In order to improve flow resistance on stepwise mesh, new analysis method, for example porous media method, etc., are being developed and implemented gradually. ${ }^{10,11)}$

Solidification analysis results are shown in Fig. 4, point A have longest solidification time among A, B, C. Solidification time $(65 \mathrm{~s})$ at point $\mathrm{A}$ is shorter than that of Campbell's experiment ( $80 \mathrm{~s})$. Thermal property of aluminum and mold, and heat transfer coefficient between casting and mold, have effect on solidification time. In those values, specific heat, heat conductivity and density are important, but they make a change by kinds of sand and binder, and by stamping level of mold. If making modification on those values, it is possible to fit the solidification time. Prediction of shrinkage defect can be acquired by relative solidification time distribution, therefore, absolute value of solidification time is not thought to be a matter of great importance. In this analysis solidification sequential order is same to the experiment, and is thought to be practical.

Those mentioned above are thought to show relatively good correspondence between analysis and experiment, however, the analysis result make a great change by analysis condition and property value. Therefore, it is important to apply computer simulation to actual casting process after fully verification of modeling method, analysis condition and property.
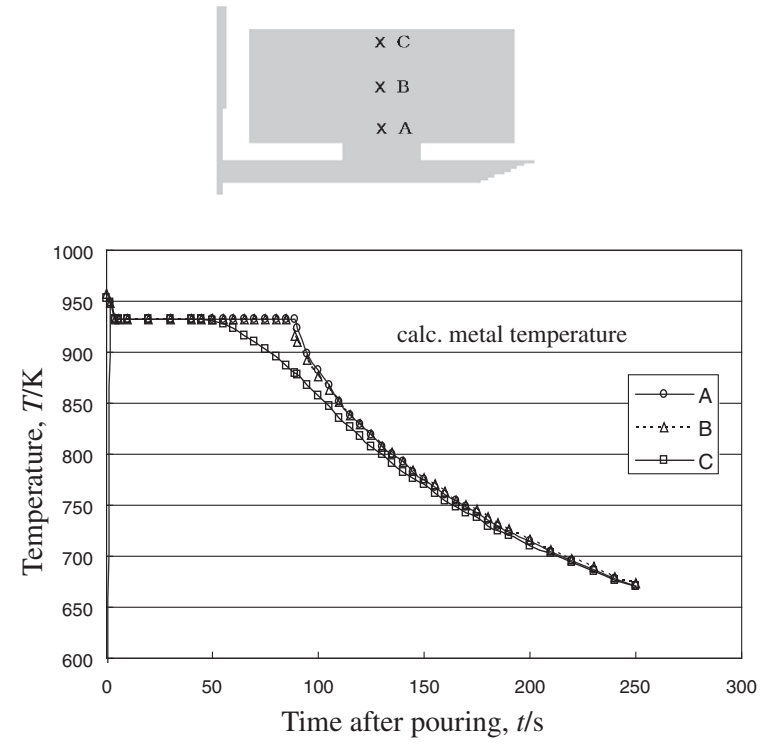

Fig. 4 Simulation results of solidification at point A, B and C.

\section{Verification in Actual High Pressure Die Casting}

\subsection{Calculation condition of high pressure die casting}

Based on analysis conditions of aluminum sand casting mentioned above, a series of experiments and verifications in an actual high pressure die casting is done.

(1) Model of aluminum die casting (Fig. 5)

Casting: $215 \mathrm{~mm}$ width, $200 \mathrm{~mm}$ height, $230 \mathrm{~mm}$ length, $7.6 \mathrm{~kg}$ mass

Mesh size: $2.5 \mathrm{~mm}$, total number of elements: about 7 million

Air vent size: $1 \mathrm{~mm}$ thickness, $20 \mathrm{~mm}$ width, $200 \mathrm{~mm}$ length

Air vent location: outside of 6 over-flows

(2) Calculation condition

Analysis type: molten metal flow and solidification

Flow on boundary: complete slip condition

Cycle calculation: none 
(3) Applied physical and thermal properties for calculation Casting alloy (ADC12): specific heat $(0.963 \mathrm{~kJ} / \mathrm{kgK})$, density $\left(2650 \mathrm{~kg} / \mathrm{m}^{3}\right)$, thermal conductivity $(126.6 \mathrm{~W} / \mathrm{mK})$, solidification temperature $(863-843 \mathrm{~K})$, latent heat $(389.3$

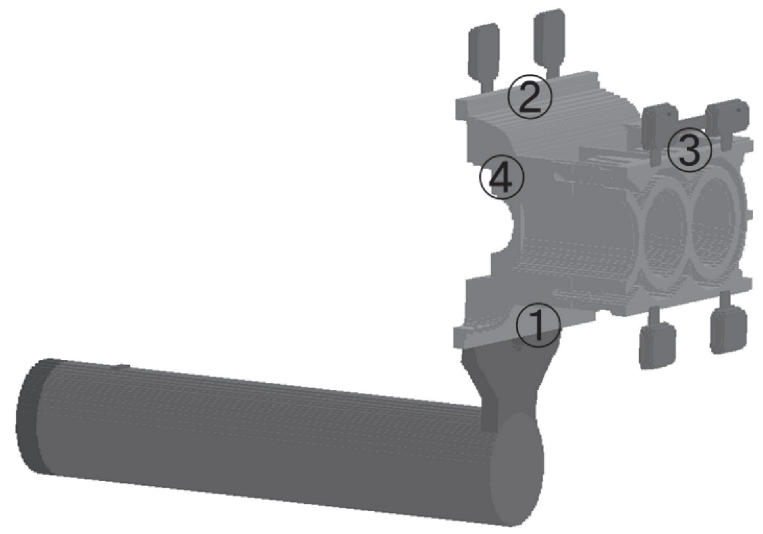

Fig. 5 Simulation model of aluminum high pressure die casting and sensor positions $(1,2,3,4)$.

(a)
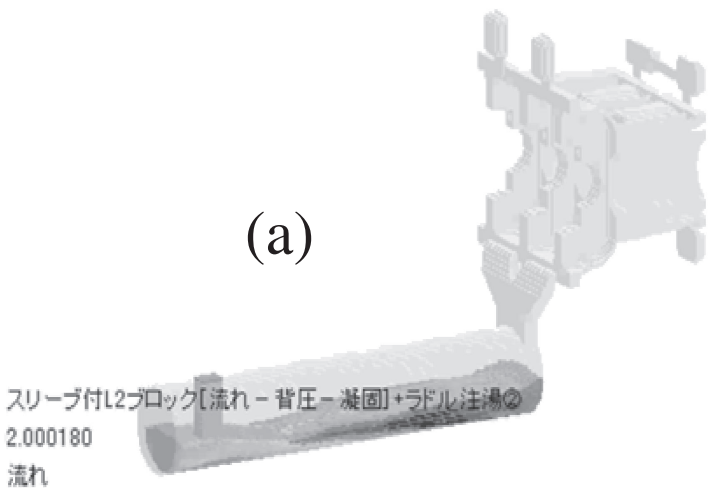

温庶

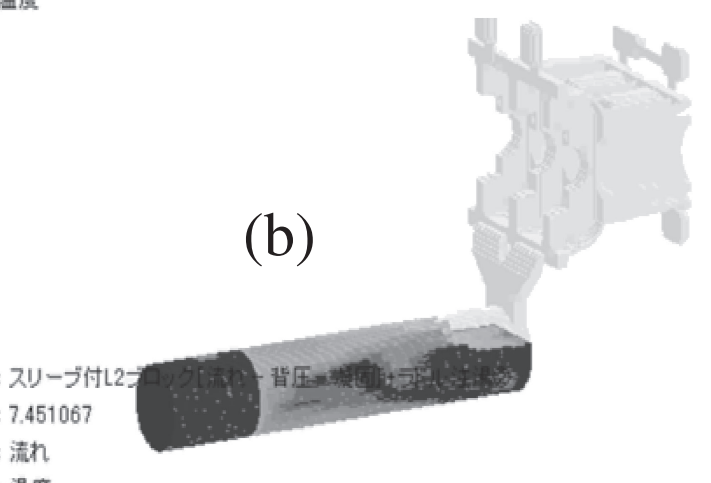

温度

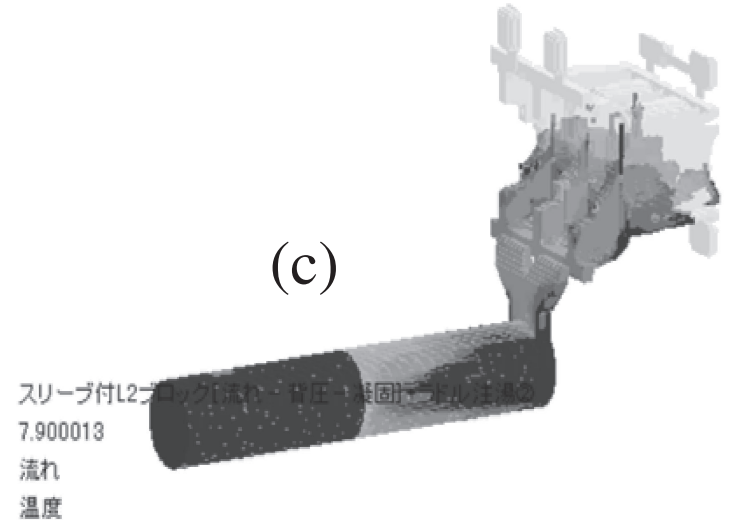

$\mathrm{kJ} / \mathrm{kg})$, kinematic viscosity $\left(0.01 \mathrm{~cm}^{2} / \mathrm{s}\right)$

Die (SKD61): specific heat $(0.502 \mathrm{~kJ} / \mathrm{kgK})$, density $\left(7750 \mathrm{~kg} / \mathrm{m}^{3}\right)$, thermal conductivity $(29.3 \mathrm{~W} / \mathrm{mK})$

Heat transfer coefficient: between casting and die (6237 $\left.\mathrm{W} / \mathrm{m}^{2} \mathrm{~K}\right)$

(4) Initial condition: Pouring temperature (923 K), Die

(473 K constant), Initial filling rate of injection sleeve (50\%)

(5) Injection condition

Die cast machine: $8000 \mathrm{kN}$ (regular horizontal type)

First injection speed: $0.1-0.3 \mathrm{~m} / \mathrm{s}(0-350 \mathrm{~mm})$

Second injection speed: $1.5-2.0 \mathrm{~m} / \mathrm{s}(350-500 \mathrm{~mm})$

(6) Output data

Temperature distribution, Filling time, Shrinkage porosity prediction, Gas entrapment prediction, Back pressure distribution

\subsection{Examples of mold flow and solidification results}

An example of flow and solidification results in condition of first speed $0.3 \mathrm{~m} / \mathrm{s}$ and second speed $1.5 \mathrm{~m} / \mathrm{s}$ is shown in Fig. 6. Sequential process of die cast follows,

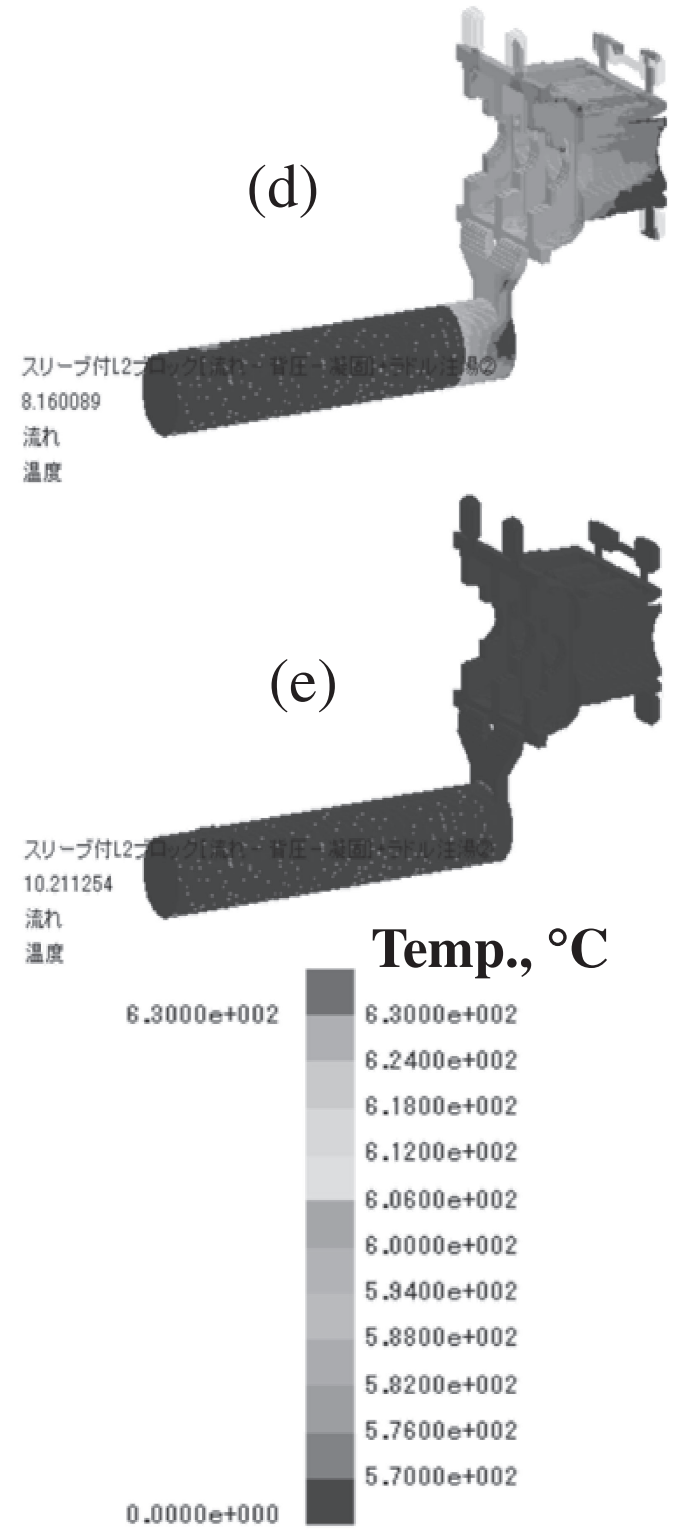

Fig. 6 Examples of flow and solidification simulation result; (a) pourting, (b) (c) first injection, (d) second injection and (e) solidification. 

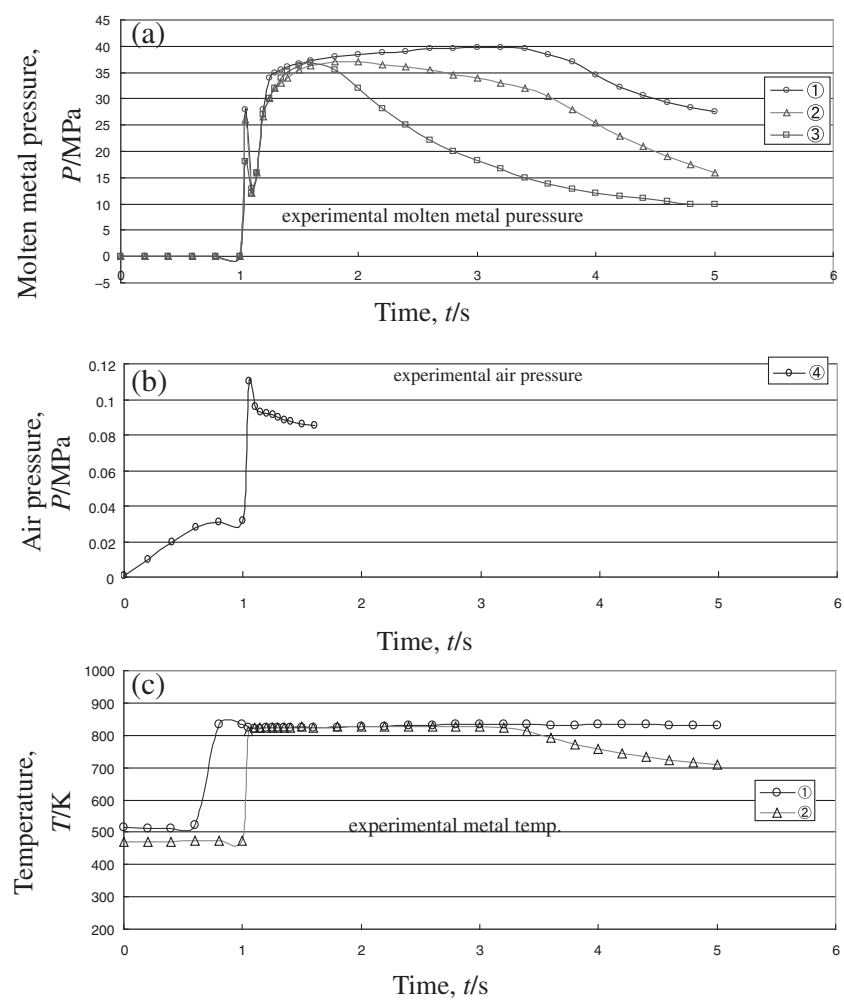

Fig. 7 Experimentally measured results; (a) molten metal pressure, (b) air pressure in die cavity and (c) metal temperature.

\section{$0-5.2 \mathrm{~s}$ : Pouring to injection sleeve}

5.2-7.0 s: Delay of injection

$7.0-8.0 \mathrm{~s}$ : First injection $(0.3 \mathrm{~m} / \mathrm{s})$

(30\% filling rate of casting part)

$8.0-8.1 \mathrm{~s}$ : Second injection $(1.5 \mathrm{~m} / \mathrm{s})$

When pouring to injection sleeve after $2 \mathrm{~s}$, thin layer solidified that cause scattered chill structure can be observed on far end of injection sleeve. After beginning first injection at $7.5 \mathrm{~s}$, small waves occur and move to runner. At the end of first injection at $7.9 \mathrm{~s}$, molten metal makes splash into die cavity. Changing to second injection at $7.9 \mathrm{~s}$, molten metal reaches to over-flows at $8.1 \mathrm{~s}$, and then mold filling finish. Solidification on casting surface finish at $10 \mathrm{~s}$.

\subsection{Experimental verification of back pressure and solidification}

Quantitative experiments for molten metal behavior is practiced with various kinds of sensors located in die. ${ }^{12)}$ In this experiment molten metal pressure sensors, back pressure sensors and solidification sensors are located at (1) frange position near gate, (2) frange position at opposite side of gate (3) frange position in moving die (4) crank journal position in Fig. 5. Those experimental results are shown in Fig. 7. Start point of passing time shown in Fig. 7 is beginning time of first injection. Experimental molten metal pressure in casting cavity shown in Fig. 7(a) has a peak by surging at the moment of stroke end, and after a while pressure value increases. Maximum pressure $40 \mathrm{MPa}$ at position (1) near injection plunger is measured, and holds till $2.5 \mathrm{~s}$, and decreases gradually. On the other hand, pressure $37 \mathrm{MPa}$ at the remote position (2) (3) is measured, and holds till about $1 \mathrm{~s}$ or less.
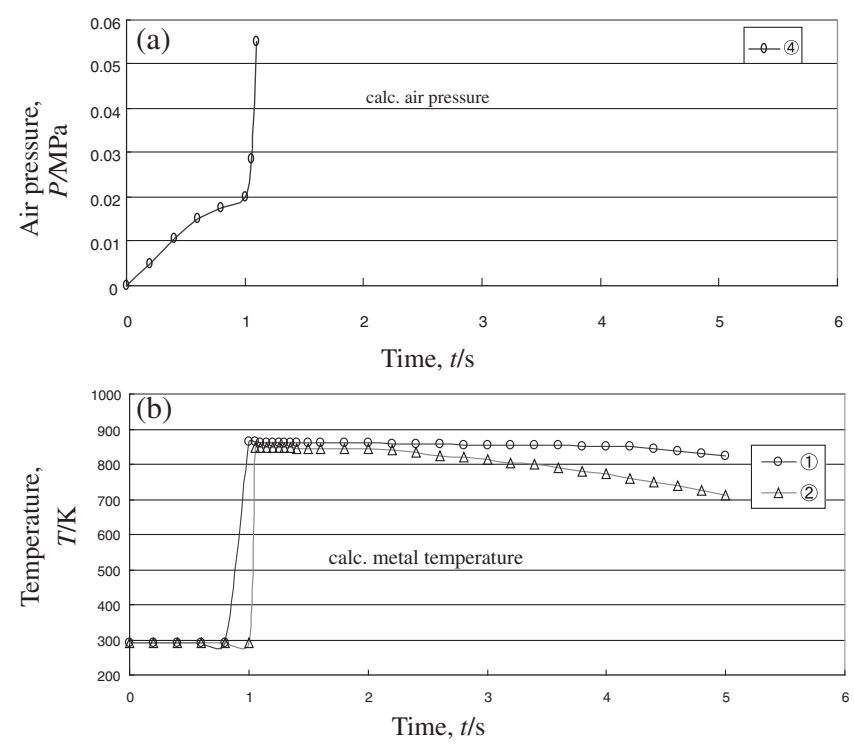

Fig. 8 Simulation results; (a) back air pressure in die cavity and (b) metal temperature.

Gas pressure in die cavity (4) shown in Fig. 7(b) increases gradually to $0.032 \mathrm{MPa}$ in accordance with first stage injection of lower speed. In second stage injection of higher speed it increases sharply and the measurement become impossible by filling of molten metal. Analysis results (4) corresponding to experimental back pressure is shown in Fig. 8(a), it increases to $0.019 \mathrm{MPa}$ till filling end, and increase sharply after changing point of second stage injection of higher speed. The shape of both curve are in good coincidence, and experimental value is higher than that of analysis. In analysis, it is assumed that gas in die cavity escapes outside only through vent holes, however, in actual phenomenon there exist a number of complicated factors influencing gas movement. They are plugging of vent hole, leakage from parting surface and injection clearance, gas occurrence from plunger lubricant and parting agent, etc. Therefore, it is difficult to predict absolute gas pressure precisely, but it is thought to be possible sufficiently to predict the tendency of vent and optimize location and shape of vent holes by this analysis method of air vent.

Experimental data of solidification are shown in Fig. 7(c), and analysis results are shown in Fig. 8(b). Experimental temperature data of thermo-couple indicated over $473 \mathrm{~K}$ nearly equal to die temperature. On the other hand, analysis results indicate $293 \mathrm{~K}$, that is, initially set value, and the value is replaced to temperature of molten metal flow in the simulation program. Therefore, those temperature differences have no problem, and the temperature curve should be compared after mold filling. Solidification finishing time at position (1) is over $4 \mathrm{~s}$ after mold filling in the experiment, and the time at position (2) is $2 \mathrm{~s}$. On the other hand, solidification time by analysis at position (1) is $4 \mathrm{~s}$, and the time at position (2) is $1.5 \mathrm{~s}$, which are faster than those of experiments. Those difference is thought to be influenced with initial die temperature (analysis $473 \mathrm{~K}$ constant), condition of heat transfer coefficient between casting and die, and etc. For better accuracy, die temperature distribution condition by cyclic calculation involving water cooling, air cooling and lubricant coating and etc. is needed. 


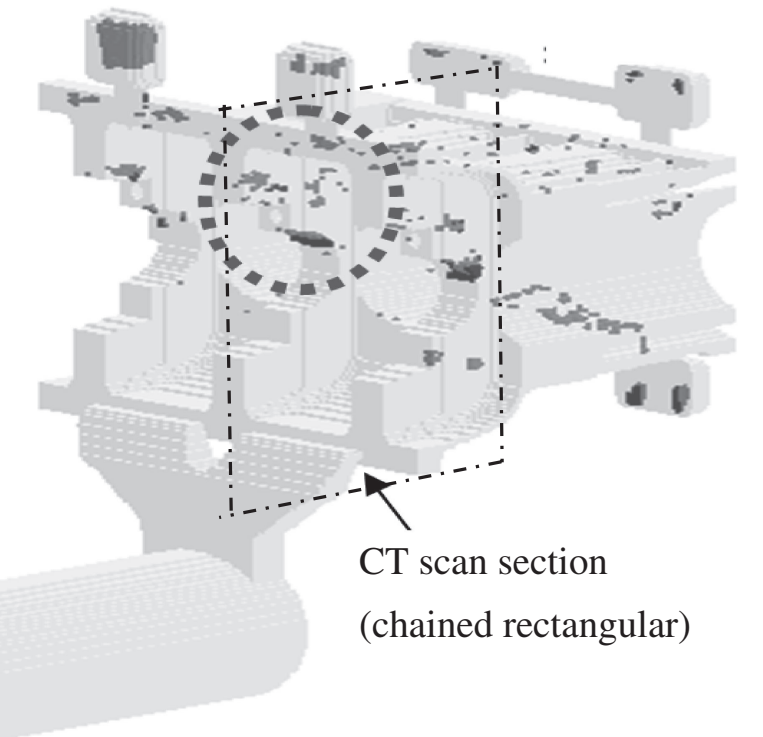

Fig. 9 Simulation result of positions of high air pressure in die cavity (dashed circle: gas entrapment defects on chained rectangular area).

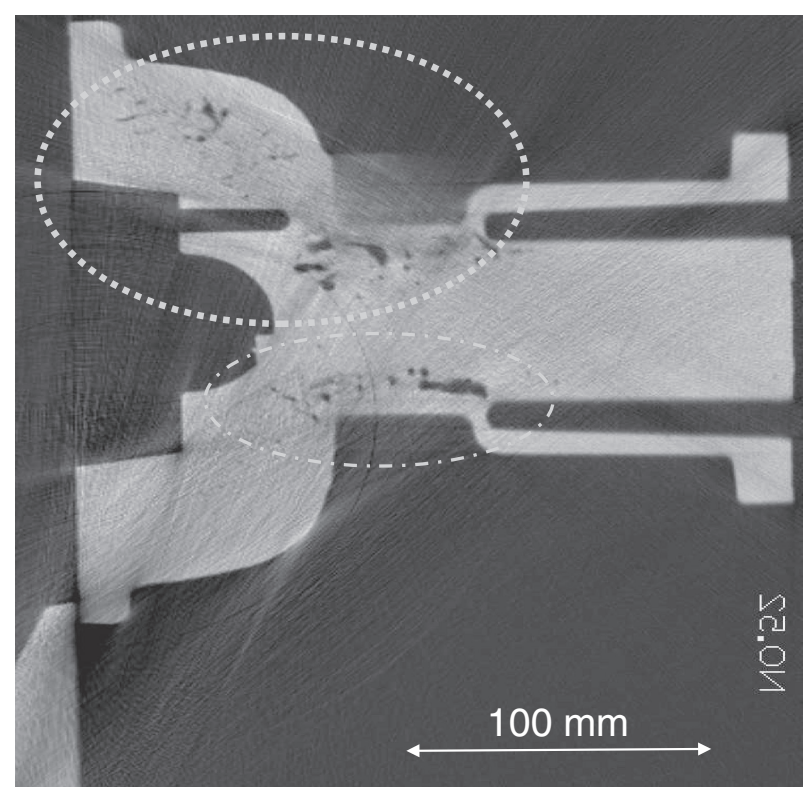

Fig. 10 Casting defects observed by CT scan on chained rectangular area in Fig. 9 (upper dotted circle: gas entrapment defects, lower chained circle: shrinkage porosity defects).

\subsection{Gas entrapment defect occurrence}

Positions with high back pressure (over $2 \mathrm{MPa}$ ) are shown in Fig. 9. Back pressure is higher especially in high speed injection stage, and high back pressure positions are scattered in areas far from gates. Those positions are consistent with actual casting defects by CT scan (Fig. 10 upper dotted line circle). If casting pressure is increased, those gas entrapment defects are thought to shrink gradually, and small defects could be vanished. And those gas entrapment defects could be changed to blister defects when heated.

\subsection{Shrinkage porosity defect occurrence}

Shrinkage porosity defects are calculated by shrinkage rate method $^{3)}$ in which shrinkage rate of each element at each

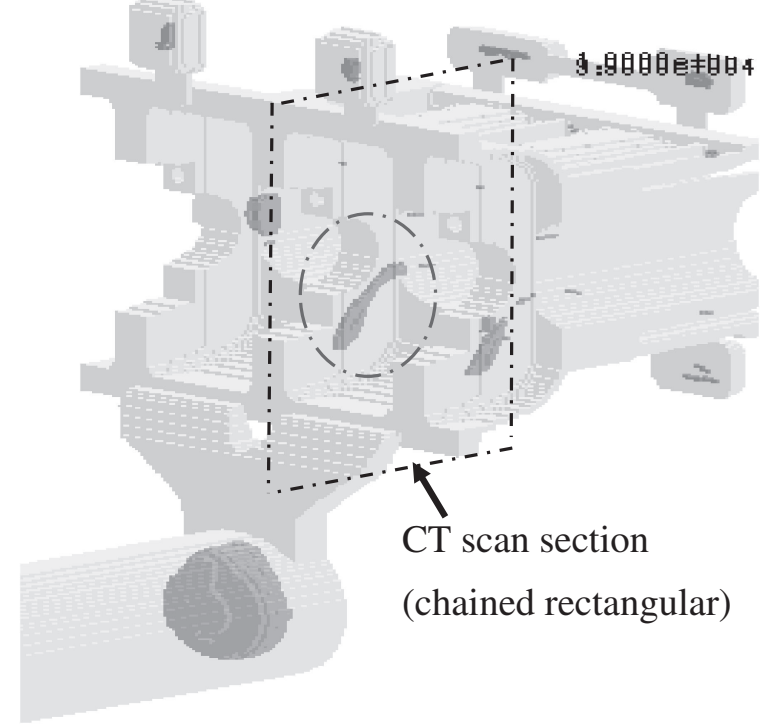

Fig. 11 Simulation result of shrinkage porosity defects (chained circle: shrinkage porosity defect on chained rectangular area).

time step is calculated by distribution of shrinkage volume depending on the solidification process. An example of shrinkage porosity defect prediction is shown in Fig. 11, and those shrinkage porosity defects are coincident with actual shrinkage porosity defects shown in Fig. 10 (lower dashed line circle). As mentioned previously, shrinkage porosity defect could be predicted accurately if holding relative solidification sequential order.

\section{Conclusions}

In order to apply casting CAE for casting design and casting plan in actual high pressure die casting process, quantitative effects and reliability of various analysis methods and conditions were experimentally verified in a simple aluminum sand casting, and an actual high pressure die casting.

(1) Slip condition between casting and die has significant effect on flow analysis, and non-slip condition makes flatter flow surface than actual flow in simple sand casting. Therefore, under the present limitation of element number, complete slip condition is more advantageous than non-slip condition in analysis accuracy.

(2) Kinematic viscosity, mesh size and mesh direction have likewise significant effects on flow analysis. Coarse mesh shows less waves or splashes, therefore is useful for quick analysis for rough flow pattern.

(3) A series of pouring-injection analysis and experimental measurements in actual high pressure die casting process were practiced and verified. Gas flow through air vent was assumed Poisseuille's flow between narrow parallel plates. Both ascending curves of back air pressure in die cavity indicated good coincidence, and experimental value was higher than that of analysis. It is thought that plugging of vent hole, gas occurrence from plunger lubricant and parting agent, and etc., affected to the difference. High back pressure distribution was in agreement with gas entrapment defects by CT scan. 
(4) Solidification time by analysis was a little shorter than that of experiments, however shrinkage porosity defect distribution by shrinkage rate method showed almost similar results.

In current circumstances, casting CAE has become essential tools. However, it could not completely simulate complicated phenomena in actual casting, and could approximate with lots of assumptions. Because mold filling and solidification analysis is non-steady and non-linear and because casting shape is complicated, the analysis is compelled to make simpler model for shorter calculation time and smaller memory size. Therefore, working out countermeasure for better casting quality by simulation and estimation of actual phenomena, it is very important to understand and verify analysis methods, simplifications, preconditions, etc.

\section{Acknowledgments}

The author is deeply grateful to the people concerned in Toyota Motor Corporation and Toyota Central R\&D Labs., Inc., for their helps in analysis and experiment.

\section{REFERENCES}

1) Japan Foundry Engineering Society: Kenkyu-hokoku98, 2006/3.

2) Japan Foundry Engineering Society: Kenkyu-hokoku105, 2011/7.

3) Y. Otsuka: J. JFS 82 (2010) 784-788.

4) C. W. Hirt, B. D. Nichols and N. C. Romero: "SOLA" A Numerical Solution Algorithm for Transient Fluid Flows, LA-5852, (1975).

5) B. D. Nichols, C. W. Hirt and R. S. Hotchkiss: "SOLA-VOF" A Solution Algorithm for Transient Fluid Flow with Multiple Free Boundaries, LA-8355, (1980).

6) I. Ohnaka: Computer Heat Transfer and Solidification Analysis, (Maruzen, 1985) (in Japanese)

7) http://www.toyota-cs.com/.

8) The Japan Society of Mechanical Engineers: Kikai-Kogaku-Binran, (1987) A5-76.

9) B. Sirrell, M. Holliday and J. Campbell: The 7th Conference on the Modeling of Casting, Welding, and Advanced Solidification Process 1995, Benchmark Test 1995, (TMS, 1995) p. 915.

10) T. Nakamichi, Y. Otsuka and Y. Maeda: J. JFS 81 (2009) 384-388

11) Y. Maeda, Y. Otsuka and T. Nakamichi: J. JFS 81 (2009) 509-514.

12) Y. Iwata, S. Dong, Y. Sugiyama and Y. Iwahori: J. JFS 83 (2011) 421426. 